\title{
Pharmacology of antacids
}

\section{KD Pegu}

Department of Anaesthesiology, School of Clinical Medicine, Faculty of Health Sciences, University of the Witwatersrand, South Africa Corresponding author, email: kyleshpegu@yahoo.com

\section{Summary}

Antacids are usually alkaline substances that are used to neutralise excess acid in the stomach. Antacids were developed based on the hydroxides and carbonates of the group II and III metals, as well as the bicarbonates of the alkali metals. Antacids can be classified into two main classes being non-absorbable or absorbable antacids. Non-absorbable antacids have fewer side effects and further advantageous properties. Each antacid has a specific active ingredient which has a different effect on the gastric acid. Antacids act similar to when an acid reacts with a hydroxide; a salt and water are produced. Antacids are more effective in the form of suspension. The average therapeutic dose of an antacid is $10-15 \mathrm{ml}$ of liquid or one to two tablets three to four times a day. These drugs have small volumes of distribution, undergo minimal hepatic metabolism and are excreted in faeces. Antacids that contain calcium, magnesium and aluminium ions are chelators. To avoid undesirable interactions, antacids are usually used two hours before or after taking any medication.

Stress ulcerations are common in intensive care unit (ICU) patients. The pathophysiology of the ulceration probably results from an imbalance between mucosal protection and gastric acid hypersecretion. Whilst prophylaxis was provided to every patient previously, it is wise to individualise the decision and to only provide it to high risk patients. For critically ill patients who are able to receive enteral medications and in whom prophylaxis is indicated, an oral proton pump inhibitor (PPI) is preferred rather than an alternative prophylactic agent. For critically ill patients who cannot receive enteral medications, an intravenous (IV) histamine 2 $\left(\mathrm{H}_{2}\right)$ receptor blocker or IV PPI can be administered. Where PPIs or $\mathrm{H}_{2}$ blockers cannot be administered, sucralfate is a suitable oral alternative.

Keywords: antacid, gastric acid, ulcer prophylaxis

In its simplest form, antacids are drugs that are usually alkaline substances that are used to neutralise excess acid in the stomach. Excess secretion of acid into stomach or impaired resistance by the lining of the stomach or reflux into the oesophagus may produce symptoms and the treatment of these symptoms is by reducing the acidity in the stomach.

\section{Indications ${ }^{1}$}

- Gastric oesophageal reflux disease

- Gastric and duodenal ulcers

- Acute/chronic gastritis and gastroduodenitis

- Gastropathy secondary to non-steroidal anti-inflammatory drugs (NSAIDs)

- Pain and dyspeptic syndromes

- Cholecystitis

- Biliary dyskinesia

- Chronic pancreatitis

- Prevention of stress ulcers

\section{Classification}

Antacids were developed based on the hydroxides and carbonates of the group II and III metals, as well as the bicarbonates of the alkali metals. All antacids contain at least one of the following metals: aluminium, calcium, magnesium, sodium, potassium, or bismuth. ${ }^{2}$ Antacids can be classified into two main classes, namely absorbable and non-absorbable antacids. ${ }^{1,2}$

\section{Absorbable antacids}

These are soluble, readily absorbable and capable of producing systemic electrolyte abnormalities. Properties include:

- Absorbed into the systemic circulation. ${ }^{1,2}$

- They have a cationic group that does not form insoluble basic compounds with a bicarbonate ion $\left(\mathrm{HCO}_{3}{ }^{-}\right)$hence the $\mathrm{HCO}_{3}{ }^{-}$ can be absorbed.

\section{- Rebound phenomenon ${ }^{1,2}$}

This is a physiological response to alkalisation of the medium, which activates the secretion of hydrochloric acid $(\mathrm{HCl})$. Implemented by the stimulation of production of gastrin and the direct effect of calcium on the parietal cells of the stomach mucosa. Many medications in this group contribute to the mechanical distension of the stomach wall, which in itself is a potent stimulus of acid.

\section{- Short lived effect ${ }^{1,2}$}

Immediate but short effects increase dosing intervals thus increase the chances of complications.

- Altered acid base balance $e^{1,2}$

- Alters acid base in the favour of a metabolic alkalosis. 
- Reduced gastric and intestinal emptying ${ }^{3}$

- Tendency of constipation.

- Undesirable effects on pregnant woman and elderly ${ }^{3}$

\section{Non-absorbable antacids ${ }^{1,2}$}

These avoid the abovementioned complications. Properties include:

- Compounds that are not absorbed into the systemic circulation.

- Their anionic group neutralises the hydrogen ions $\left(\mathrm{H}^{+}\right)$in gastric acid. This releases their cationic group which combine with $\mathrm{HCO}_{3}^{-}$from the pancreas to form an insoluble basic compound that is excreted in faeces.

- These agents do not produce a metabolic alkalosis.

- Accumulation of calcium $\left(\mathrm{Ca}^{2+}\right)$, magnesium $\left(\mathrm{Mg}^{2+}\right)$ and aluminium $\left(\mathrm{Al}^{2+}\right){ }^{3}$

Dangerous with use in renal insufficiency with aluminium compounds being contraindicated in renal insufficiency.

- Encephalopathy ${ }^{4}$ and arthropathy ${ }^{5}$

Occurs with chronic administration of mainly bismuth $\left(\mathrm{Bi}^{3+}\right)$ compounds.

\section{- Nephrolithiasis ${ }^{6}$}

Occurs with silicon containing compounds.

- Phosphate deficiency syndrome ${ }^{3}$

\section{Advantageous properties of non-absorbable antacids ${ }^{2}$}

- Absorb pepsin, resulting in reduced proteolytic activity of gastric acid.

- Connect lysolecithin and bile acid which have a damaging effect on the gastric mucosa.

- Possess cytoprotective function through the activation of prostaglandin synthesis which stimulates secretion of mucin and bicarbonates, improve microcirculation.

- Possess ambient function, forming a protective film on the gastric mucosal surface.

- Able to bind epithelial growth factor and fix the ulcerous defect region effectively stimulating cell proliferation and angiogenesis.

\section{Examples of antacids}

Table I: Examples of antacids

\begin{tabular}{ll}
\hline Absorbable & Non-absorbable \\
\hline Sodium bicarbonate & $\begin{array}{l}\text { Aluminium salt of phosphoric } \\
\text { acid, e.g. phosphalugel }\end{array}$ \\
\hline Calcium carbonate & $\begin{array}{l}\text { Aluminium magnesium } \\
\text { antacids, e.g. Almagel }\end{array}$ \\
\hline $\begin{array}{l}\text { Bourget mixture (sulphate, } \\
\text { sodium, sodium phosphate) }\end{array}$ & $\begin{array}{l}\text { Aluminium magnesium antacids } \\
\text { with other components }\end{array}$ \\
\hline $\begin{array}{l}\text { Rennies (calcium carbonate and } \\
\text { magnesium carbonate) }\end{array}$ & Magnesium hydroxide \\
\hline Magnesia (magnesium oxide) & Magnesium salicylate \\
\hline Magnesium carbonate & \\
\hline
\end{tabular}

\section{Properties of differing compounds ${ }^{1}$}

Table II: Properties of compounds

\begin{tabular}{lcccc}
\hline \multirow{2}{*}{ Effect } & \multicolumn{4}{c}{ Cations } \\
\cline { 2 - 5 } & $\mathbf{A l}^{2+}$ & $\mathbf{M g}^{2+}$ & $\mathbf{C a}^{2+}$ & $\mathbf{B i}^{\mathbf{2 +}}$ \\
\hline Neutralising & $++/+++$ & +++ & + & - \\
Absorbing & + & - & - & - \\
Ambient & + & - & - & +++ \\
Astringent & +++ & + & + & + \\
Cytoprotective & +++ & - & - & + \\
\hline
\end{tabular}

- - no effect, + - low activity, ++ - average activity, +++ - high activity

\section{Physiology of gastric acid secretion ${ }^{7}$}

- Gastric secretions include pepsin, gastric lipase, hydrochloric acid, mucus, gastrin and intrinsic factor. Total secretion is roughly two litres per day with a $\mathrm{pH}$ of $1-1.5$. These secretions are slightly hyperosmotic, high in potassium $\left(\mathrm{K}^{+}\right)(10 \mathrm{mmol} / \mathrm{L})$, $\mathrm{H}^{+}(150-170 \mathrm{mmol} / \mathrm{L})$, chloride $\left(\mathrm{Cl}^{-}\right)(180 \mathrm{mmol} / \mathrm{L})$ and low in sodium $\left(\mathrm{Na}^{+}\right)$(2-4 mmol/L).

- The gastric mucosal barrier keeps $\mathrm{H}^{+}$out of the mucosa and $\mathrm{Na}^{+}$ions in, while maintaining a potential difference across the surface of the mucosa. This is the defence against autodigestion and ulceration by $\mathrm{HCl}$.

- Parietal cells in the body and fundus secrete $\mathrm{HCl}$ and intrinsic factor.

- $\mathrm{HCl}$ facilitates breakdown of protein and provides the optimal $\mathrm{pH}$ for pepsin activity.

- The specific production of $\mathrm{H}^{+}$comes from the gastric parietal cell from the following mechanisms:

- Receptors for histamine, acetylcholine and gastrin are located on the basolateral membrane of the parietal cell and stimulate acid secretion.

- Somatostatin, epidermal growth factor, beta adrenergic agonists and enteroglucagon inhibit acid secretion by indirect mechanisms.

- The $\mathrm{H}^{+}$ion is derived from the dissociation of water $\left(\mathrm{H}_{2} \mathrm{O}\right)$. $\mathrm{H}_{2} \mathrm{O}$ is formed by the $\mathrm{OH}^{-}$combined with an $\mathrm{H}^{+}$derived from the dissociation of carbonic acid $\left(\mathrm{H}_{2} \mathrm{CO}_{3}\right) . \mathrm{H}_{2} \mathrm{CO}_{3}$ is formed by $\mathrm{H}_{2} \mathrm{O}$ combining with carbon dioxide $\left(\mathrm{CO}_{2}\right)$ with the $\mathrm{CO}_{2}$ being derived from metabolism.

- Across the apical membrane the $\mathrm{H}^{+}$ion is exchanged for $\mathrm{K}^{+}$ by the $\mathrm{H}^{+} / \mathrm{K}^{+}$ATPase pump.

- At the basolateral membrane, the $\mathrm{Cl} / \mathrm{HCO}_{3}{ }^{-}$exchanger is stimulated by $\mathrm{H}^{+}$secretion. The chloride ions leak out of the apical membrane as a result of the electrochemical gradient.

\section{Mechanism of action of antacids ${ }^{2}$}

- Each antacid has a specific active ingredient. This ingredient whether metallic or non-metallic has a different effect on the gastric acid. Antacids act similar to when an acid reacts with a hydroxide; a salt and water are produced as in the following equation: $\mathrm{HCl}(\mathrm{aq})+\mathrm{NaOH}(\mathrm{aq}) \rightarrow \mathrm{NaCl}(\mathrm{aq})+\mathrm{H}_{2} \mathrm{O}$

- Sodium bicarbonate: $\mathrm{HCl}(\mathrm{aq})+\mathrm{NaHCO}_{3}(\mathrm{aq}) \rightarrow \mathrm{NaCl}(\mathrm{aq})+$ $\mathrm{H}_{2} \mathrm{O}+\mathrm{CO}_{2}$. 
- Calcium carbonate: $\mathrm{HCl}(\mathrm{aq})+\mathrm{CaCO}_{3}(\mathrm{aq}) \rightarrow \mathrm{CaCl}_{2}(\mathrm{aq})+\mathrm{H}_{2} \mathrm{O}$ $+\mathrm{CO}_{2}$

- Magnesium compounds: $\mathrm{MgO}+\mathrm{H}_{2} \mathrm{O} \rightarrow \mathrm{Mg}(\mathrm{OH})_{2} ; \mathrm{HCl}(\mathrm{aq})+$ $\mathrm{Mg}(\mathrm{OH})_{2} \rightarrow \mathrm{MgCl}_{2}+\mathrm{H}_{2} \mathrm{O}$

- Aluminum compounds: $\mathrm{Al}(\mathrm{OH})_{3}+\mathrm{HCl} \rightarrow \mathrm{AlCl}_{3}+\mathrm{H}_{2} \mathrm{O}$

Administration ${ }^{2,8}$

- Antacids are used in the form of tablets and suspensions.

- Antacids react with hydrogen ions only in a solute form suspensions consist of smaller particles, they have a larger surface area and are dissolved faster in an acidic environment when compared to tablets. Antacids are more effective in the form of suspension.

- The average therapeutic dose of an antacid is $10-15 \mathrm{ml}$ of liquid or one to two tablets three to four times a day.

- When antacids are taken on an empty stomach they are rapidly emptied into the duodenum, in addition their effect is negated because food acts as a buffer for antacids. Antacids should be prescribed 1-1.5 hours after meals.

- Periodic monitoring of calcium and phosphorus levels is a suggested practice in patients on chronic therapy. Careful dosing must occur in those with hepatic and renal impairment.

\section{Metabolism²}

- These drugs have small volumes of distribution, undergo minimal hepatic metabolism and are excreted in faeces.

\section{Contraindications ${ }^{8}$}

- Renal failure

- Cardiac failure

- Oedema

- Cirrhosis

- Low sodium diet

- Uraemia

- Upper GI bleed

- Hyperparathyroidism

- Renal calculi

\section{Drug interactions ${ }^{1}$}

- Antacids that contain calcium, magnesium and aluminium ions are chelators. They bind a great number of drugs such as digitoxin, tetracycline, indomethacin, aspirin, cimetidine, ranitidine, famotidine, theophylline, etc.

- Antacids also reduce the bioavailability of drugs like barbiturates, sulphonamides, and penicillin.

- To avoid undesirable interactions, antacids are usually used two hours before or after taking any medication.

\section{Ulcer prophylaxis in the intensive care unit}

Stress ulcerations are common in ICU patients, some of which can cause haemorrhage. Many critically ill patients require prophylaxis for the primary prevention of bleeding from stress ulcers. Stress ulcerations usually occur in the fundus and body of the stomach, but sometimes develop in the antrum, duodenum or distal oesophagus. The pathophysiology of the ulceration probably results from an imbalance between mucosal protection and gastric acid hypersecretion. The administration of stress ulcer prophylaxis is an area of topical debate. Whilst prophylaxis was provided to every patient previously, it is wise to individualise the decision and to only provide it to high risk patients. ${ }^{9}$

Criteria include: ${ }^{9}$

- Bleeding diathesis, e.g. platelet count $<50$, INR $>1.5$, PTT $>2$ $x$ normal.

- Mechanical ventilation for $>48$ hours.

- History of Gl ulceration or Gl bleeding within the past year.

- Traumatic brain injury, traumatic spinal cord injury, or burn injury.

- Two or more of the following minor criteria: sepsis, an ICU stay more than one week, occult Gl bleeding for six or more days, or glucocorticoid therapy (more than $250 \mathrm{mg}$ hydrocortisone or the equivalent).

- On NSAIDs or antiplatelet agents.

\section{Pharmacological agents}

\section{Proton pump inhibitors, e.g. omeprazole, lansoprazole and esomeprazole ${ }^{10}$}

- PPIs bind irreversibly and noncompetitively to the $\mathrm{H}^{+} / \mathrm{K}^{+}$ ATPase pump thus causing a rise in gastric $\mathrm{pH}$ but do not increase gastric emptying.

- Require 72 hours to reach peak effect.

- Inhibit the activity of CYP450

- Omeprazole - substituted benzimidazole which inhibits the proton pump and reduces secretion. It is a weak base with a pKa of 4 and thus accumulates in the acidic milieu of the parietal cells where it is protonated to form its active form $\mathrm{H}$-omeprazole.

- Esomeprazole - S isomer of omeprazole. More potent and effective since it follows zero order kinetics. Half the standard dose $(20 \mathrm{mg})$ raises gastric $\mathrm{pH}$ above four for at least 16 hours in $24 \%$ of patients - inhibits pepsin - allows mucosa to heal.

\section{Sucralfate ${ }^{10}$}

- Sulphated sucrose and polyaluminium hydroxide.

- $\mathrm{pH}$ less than four - polymerises and cross links - forms a paste that adheres to exposed protein at the base of the ulcer. Repels pepsin from ulcer proteins.

- Aluminium hydroxide adsorbs pepsin.

- It does not change the $\mathrm{pH}$ of the stomach, but it coats the ulcer and limits further injury while allowing mucosa to heal.

- In order to be activated in the acidic medium, PPI administration must be delayed by 30 minutes.

- It is safer in immunocompromised patients as it does not alter the $\mathrm{pH}$ of the stomach. 
- Side effects

- Mild constipation

- Hypophosphataemia in uraemic patients

\section{Histamine 2 receptor blockers, e.g. cimetidine, ranitidine}

- Histamine is the final common mediator for secretion of gastric acid. It potentiates the action of gastrin and acts on the gastric parietal cell as well as acting directly as a secretagogue. ${ }^{10}$

- Blocks the secretion of gastric acid - decreases gastric volume and secretion of hydrogen ions. ${ }^{10}$

- Nitrosodimethylamine, a probable human carcinogen, has been found in ranitidine and has resulted in the drug being removed from the market by the United States Food and Drug Administration. ${ }^{11}$

- Cimetidine contains an imidazole ring, has a duration of action of 4-8 hours and inhibits $70 \%$ of gastric acid secretion. Side effects are multiple drugs interactions as the cimetidine is metabolised and then binds the cytochrome P450 system, inhibition of the hepatic mixed function oxidase system, gynaecomastia and dysrhythmias. ${ }^{10}$

\section{Which agent do you use?}

Whether prophylaxis is effective and safe, or not, remains a topic of controversy. The data is still conflicting, and provision of a simple answer is not feasible at the present time. Healthcare workers working in the ICU must carefully analyse the advantage and disadvantage of each agent tailored to the patient's presentation and comorbidities. ${ }^{9}$

For critically ill patients who are able to receive enteral medications and in whom prophylaxis is indicated, an oral PPI is preferred rather than an alternative prophylactic agent. For critically ill patients who cannot receive enteral medications, an IV $\mathrm{H}_{2}$ blocker or IV PPI can be administered. While an IV PPI is preferred, some clinicians administer $\mathrm{IV}_{2}$ blockers based upon their lower cost. An increase in efficacy of PPIs over $\mathrm{H}_{2}$ blockers is uncertain, especially when the baseline risk of stress ulcer related bleeding is low. In rare cases where PPIs or $\mathrm{H}_{2}$ blockers cannot be administered, sucralfate is a suitable oral alternative. Antacids are rarely, if ever, used. ${ }^{9}$

\section{Conflict of interest}

The author declares no conflict of interest.

\section{Funding source}

None.

\section{ORCID}

KD Pegu (iD https://orcid.org/0000-0002-3977-3030

\section{References}

1. Tomina $O$, Yabluchansky $M$, Bychkova 0 , Ivleva 0 . Antacids clinical pharmacology. Journal of V N Karazin' KhNU. 2014;1141:52-7. Available from: http://oaji.net/articles/2015/1225-1437914944.pdf. Accessed 25 September 2020.

2. Mondal DS. Pharmaceutical inorganic chemistry: Gastrointestinal agents (antacid) 2017. Available from: https://www.researchgate.net/ publication/321938715_PHARMACEUTICAL_INORGANIC_CHEMISTRY_ Gastrointestinal_agents_ANTACID. Accessed 25 September 2020.

3. Vakil N. Antiulcer medications: Mechanism of action, pharmacology, and side effects 2020. Available from: https://www.uptodate.com/contents/antiulcermedications-mechanism-of-action-pharmacology-and-side-effects. Accessed 24 September 2020

4. Reynolds $\mathrm{P}$, Abalos $\mathrm{K}$, Hopp J, Williams M. Bismuth toxicity: A rare cause of neurologic dysfunction. Int J Clin Med. 2012;3(1):46-8. https://doi.org/10.4236/ ijcm.2012.31010.

5. Sun H, Zhang L, Szeto K-Y. Bismuth in medicine. Met lons Biol Syst. 2004;41:33378. Available from https://pubmed.ncbi.nlm.nih.gov/15206122/.

6. Flythe J, Rueda J, Riscoe M, Watnick S. Silicate nephrolithiasis after ingestion of supplements containing silica dioxide. Am J Kidney Dis. 2009;54:127-30. https:// doi.org/10.1053/j.ajkd.2008.10.042.

7. Kam P, Power I. Principles of physiology for the anaesthetist. 3rd ed. London England: Taylor and Francis Group; 2015. p. 187-206.

8. Salisbury B, Terrell M. Antacids. 2020. Available from: https://www.ncbi.nlm.nih gov/books/NBK526049/?report=classic. Accessed 24 September 2020.

9. Weinhouse G. Stress ulcers in the intensive care unit: diagnosis, management and prevention 2020. Available from: https://www.uptodate.com/contents/ stress-ulcers-in-the-intensive-care-unit-diagnosis-management-and-prevention. Accessed 25 September 2020.

10. Rantloane J, Brandl A, Biccard B. In: Milner A, Welch E, editors. Applied pharmacology in anaesthesiology and critical care. 1st ed. 2012. p. 406-11.

11. FDA. FDA requests removal of all ranitidine products (zantac) from the market USA2020. Available from: https://www.fda.gov/news-events/ press-announcements/fda-requests-removal-all-ranitidine-productszantacmarket. Accessed 24 September 2020. 